\title{
Comparison of the Effects of Ringer's Lactate and 6\% Hydroxyethyl Starch 130/0.4 on Blood Loss and Need for Blood Transfusion After Off-Pump Coronary Artery Bypass Graft Cardiac Surgery
}

\author{
Roshani Manwani ${ }^{1}$, Neha Gupta ${ }^{2}$, Shilpa Kanakam ${ }^{3}$, Minal Vora ${ }^{4}$, Krishnan Bhaskaran ${ }^{4}$ \\ 1. Anesthesiology, Dr. Dnyandeo Yashwantrao (DY) Patil University, School of Medicine, Navi Mumbai, IND 2. \\ Anesthesiology, Dr. Dnyandeo Yashwantrao (DY) Patil Medical College and Hospital, Navi Mumbai, IND 3. \\ Anesthesiology, Fortis Hospital, Kolkata, IND 4. Anesthesiology, Apollo Hospitals, Chennai, IND
}

Corresponding author: Neha Gupta, drng2105@gmail.com

\section{Abstract \\ Background}

Infusion of crystalloids fluid replacement therapy tends to cause a greater expansion of intravascular volume. However, colloids can affect blood coagulation leading to greater blood loss and transfusion requirements. This study compared the intraoperative and postoperative blood loss with Ringer's lactate (RL) versus 6\% hydroxyethyl starch (HES) 130/0.4 as infusion fluid during cardiac surgery.

\section{Methods}

Eighty adult male and female patients undergoing elective cardiac surgery were randomly assigned to receive either RL or 6\% HES 130/0.4 20 ml/kg during off-pump coronary artery bypass graft (OP-CABG) surgery. Intraoperative blood loss and 24 hours postoperative chest tube drainage were the primary outcomes. Simultaneously, blood transfusions, thromboelastometry variables, total fluid requirement, renal function, and intensive care unit (ICU) stay were assessed.

\section{Results}

The intraoperative blood loss was similar ( $p>0.05$ ) with HES (716 ml) and RL $(658 \mathrm{ml})$. Postoperative chest tube drainage was higher $(\mathrm{p}<0.05)$ with HES $(513 \mathrm{ml})$ as against RL $(449 \mathrm{ml})$. The total fluid requirement was higher in the RL group. Alteration of thromboelastometry variables, renal function, and ICU stay was comparable between the two groups. Postoperative chest tube drainage was less with the use of RL during cardiac surgery. A lesser total fluid requirement in the HES group did not lead to any improvement in renal function and the length of ICU stay.

Review began 06/21/2021 Review ended 06/23/2021 Published 06/30/2021

\section{๑) Copyright 2021}

Manwani et al. This is an open access article distributed under the terms of the Creative Commons Attribution License CC-BY 4.0., which permits unrestricted use, distribution, and reproduction in any medium, provided the original author and source are credited.

\section{Conclusions}

Crystalloids (RL) provide similar outcomes to HES and can be used as substitutes to colloids during cardiac surgery. However, further large-scale multicenter studies with varied indications can be suggested to substantiate the equivalence of crystalloids to colloids in perioperative management.

Categories: Anesthesiology, Cardiac/Thoracic/Vascular Surgery, Internal Medicine

Keywords: blood loss, fluid regimen, coagulation, cardiac surgery, crystalloid, colloid

\section{Introduction}

Patients with coronary artery bypass graft (CABG) surgery may be hemodynamically unstable during the immediate postoperative period and need fluid support [1]. Colloids such as hydroxyethyl starches are known to have a more profound intravascular volume expansion compared with crystalloids such as Ringer's lactate (RL) [2]. Hence, ideally, colloids should be suitable for restrictive fluid therapy during any major surgery. However, a lot of controversies still exist about the optimal perioperative fluid management in patients undergoing cardiac surgery, especially due to their effects such as inflammatory responses, effects on endothelial integrity, and effects on organs such as the kidney [3].

Five percent human albumin ( $5 \%$ HA) has been in use for a long time during cardiac surgery as a colloid. However, due to its cost and availability, colloids such as hydroxyethyl starches (HES) are being used. However, HES preparations have shown to impair coagulation and renal function $[4,5]$. HES has been reported to cause mild systemic acidosis in patients undergoing normovolemic hemodilution after cardiac surgery and impairment in fibrin formation and clot strength $[3,6]$. Also, correcting hypovolemia with HES has been suggested to be associated with an increased risk of acute renal failure [7]. Six percent HES (6\% HES $130 / 0.4$ ) is a newer generation tetra starch formulation with a lower molecular weight, which might affect 
coagulation to a lesser degree [8]. Although cheaper than HA, 6\% HES 130/0.4 is 4-10 fold dearer than crystalloids in India. Transfusion of packed red blood cells (PRBCs) fluid replacement is associated with increased morbidity and mortality after cardiac surgery [9]. RL has also been used for many years during heart surgery, either as a sole replacement fluid or in combination with colloids [10]. Because of the large volumes administered throughout the procedure, even RL might influence coagulation via dilution of coagulation factors. Impaired coagulation leads to higher perioperative blood loss, leading to a higher requirement of blood transfusion.

The aim of this study was to compare the effect of $6 \%$ HES solution with RL solution on intraoperative and postoperative blood loss when used as the main infusion during cardiac surgery in patients after CABG surgery.

\section{Materials And Methods \\ Study participants}

Patients posted for coronary artery bypass graft (CABG) surgery at the study sites were screened for eligibility based on the study inclusion/exclusion criteria. The study documents were reviewed and approved by the Institutional Ethics Committee (IEC). Male and female patients between 30 and 70 years of age who were planned to undergo elective off-pump (OP) CABG and those who signed the informed consent were included. Patients with known allergy to HES, presence of anemia, coagulation disorders (INR > 1.2), activated partial thromboplastin time $>40$ seconds, platelet count $<0.5$ million cells/cubic mm), and left ventricular ejection fraction $(\mathrm{LVEF})<40 \%$ were not included. Also, those with serum creatinine $>1.5 \mathrm{mg} / \mathrm{dl}$ or those who are receiving any anticoagulants or antiplatelet therapy within seven days before surgery were excluded. A total of 98 patients were screened out of which 80 were enrolled and randomized in this randomized, comparative, double-blind study.

\section{Randomization, blinding, and fluid regimen}

Patients were randomized to receive either RL $(n=40) 20 \mathrm{ml} / \mathrm{kg}$ body weight or HES $(\mathrm{n}=40) 20 \mathrm{ml} / \mathrm{kg}$ body weight. Randomization was performed using the sealed envelope technique. The hospital pharmacy prepared the study solutions that were supplied in identical $500 \mathrm{ml}$ bottles. Bottles and infusion sets were wrapped with opaque covers for blinding. Normal saline (0.9\%) was used as fluid for any additional requirement.

\section{Procedures}

Anesthesia was induced with thiopental (5 mg/kg) and fentanyl (5 mcg/kg), and tracheal intubation was facilitated by rocuronium $(0.6 \mathrm{mg} / \mathrm{kg})$ intravenously. Propofol $(1 \mathrm{mg} / \mathrm{kg} / \mathrm{hr})$ and fentanyl $(2 \mathrm{mcg} / \mathrm{kg} / \mathrm{hr})$ infusions were used for maintenance. Muscle paralysis was maintained with rocuronium infusion $(0.3$ $\mathrm{mg} / \mathrm{kg} / \mathrm{hr})$.

Fluid administration was started with $250-500 \mathrm{ml}$ of study solution during induction of anesthesia. The remaining allotment of the study solution was used subsequently. Any additional fluid requirement was fulfilled with $0.9 \%$ normal saline (NS) in both groups. Baseline thromboelastometry variables were measured after induction of anesthesia. All patients received the same standard dose of heparin and tranexamic acid. Activated clotting time (ACT) was measured regularly and maintained above 300 seconds till the completion of the anastomosis. After the procedure, the heparin effect was reversed using protamine (1.5 $\mathrm{mg}$ for each 100 IU of heparin given). Norepinephrine was used, if necessary, to maintain mean arterial pressure $>60 \mathrm{~mm}$ Hg. Transoesophageal echocardiography was used to assess ventricular function. Intraoperative blood loss was measured by measuring blood in the suction bottle and mops (by gravimetric method). PRBCs were transfused when hemoglobin $(\mathrm{Hb})$ was less than $7 \mathrm{gm} \%$. The administration of fresh-frozen plasma (FFP), platelets, and coagulation factors was based predominantly on thromboelastometry variables and the preoperative and postoperative coagulation profile of each patient.

After the procedure, the patient was transferred to the intensive care unit (ICU), and further fluid management and inotrope support were at the discretion of the attending consultant and not controlled by protocol. Postoperatively, the amount of chest drains for 24 hours and blood transfusion requirements were measured. Blood samples were collected to assess complete blood counts, renal function tests, and thromboelastometry 24 hours after surgery.

\section{Statistical analysis}

All the continuous variables were assessed for normality using Shapiro-Wilk test. Normally distributed data are presented as means with standard deviation (SD), whereas non-normal data are presented as medians with interquartile range (IQR). All the categorical variables were expressed either as percent or proportion. Comparison of normally distributed continuous variables was done by independent sample test or analysis of variance (ANOVA). Comparison of non-normally distributed continuous variables was done by MannWhitney U test or Kruskal-Wallis H test. 


\section{Cureus}

of observations. Data entry was done in Microsoft Excel (Microsoft Corporation, New Mexico, USA), and data analysis was carried out using Statistical Package for the Social Sciences (SPSS) version 17.0 (SPSS Inc., Chicago, USA). All the p-values $<0.05$ were considered statistically significant.

\section{Results}

All randomized patients completed the study as per the protocol. Figure 1 shows the CONSORT flow chart for the patient in the study. The two groups were similar with respect to the demography and baseline characteristics (Table 1).

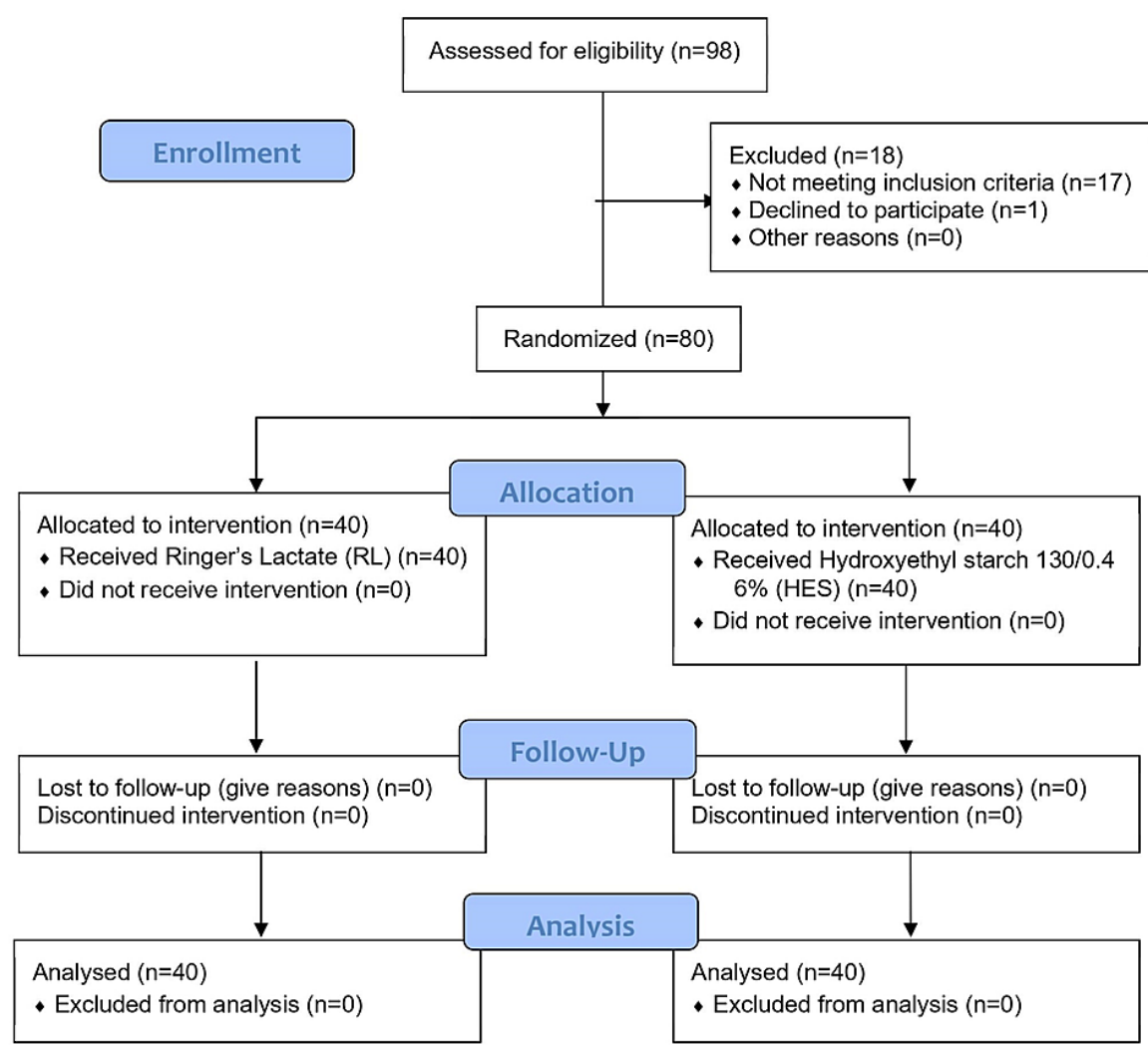

FIGURE 1: CONSORT 2010 flow diagram 


\section{Cureus}

\begin{tabular}{|c|c|c|c|c|c|c|}
\hline & \multirow{2}{*}{$\begin{array}{l}\mathrm{RL}(\mathrm{n}=40) \\
\text { Mean (SD) }\end{array}$} & \multirow{2}{*}{$\begin{array}{l}\text { HES }(n=40) \\
\text { Mean (SD) }\end{array}$} & \multicolumn{4}{|c|}{ Independent Sample t-Test } \\
\hline & & & $\mathrm{t}$ & $\mathbf{p}$ & Mean diff. & (95\% C.I.) \\
\hline Age (yrs) & $46.13(6.69)$ & $47.35(6.67)$ & -0.820 & 0.415 & -1.220 & $(-4.20-1.75)$ \\
\hline Weight (kg) & $68.4(8.07)$ & $66.24(9.76)$ & 1.078 & 0.285 & 2.16 & $(-1.83-6.14)$ \\
\hline Height (m) & $1.64(0.08)$ & $1.63(0.09)$ & 0.918 & 0.362 & 0.02 & $(-0.02-0.05)$ \\
\hline BMI $\left(\mathrm{kg} / \mathrm{m}^{2}\right)$ & $25.3(1.88)$ & $24.92(2.32)$ & 0.799 & 0.427 & 0.38 & $(-0.56-1.32)$ \\
\hline \multirow[t]{2}{*}{ INR (pre-operative) } & $1.01(0.04)$ & $1.02(0.06)$ & -0.941 & 0.349 & -0.01 & $(-0.03-0.01)$ \\
\hline & No. (\%) & No. (\%) & & $\mathrm{P}^{*}$ & & \\
\hline \multicolumn{7}{|l|}{ Gender } \\
\hline Male & $37(92.50 \%)$ & $34(85.00 \%)$ & & 0.481 & & \\
\hline Female & $3(7.50 \%)$ & $6(15.00 \%)$ & & & & \\
\hline *Fisher's test & & & & & & \\
\hline
\end{tabular}

\section{TABLE 1: Demography of the randomized patients}

RL: Ringer lactate; HES: hexaethyl starch; SD: standard deviation; Cl: confidence intervals.

The pre-operative data, postoperative data, and the change from pre-operative data are presented in Table 2 for the different parameters assessed for the study. 


\section{Cureus}

\begin{tabular}{|c|c|c|c|c|c|c|}
\hline & \multirow{2}{*}{$\begin{array}{l}\mathrm{RL}(\mathrm{n}=40) \\
\text { Mean (SD) }\end{array}$} & \multirow{2}{*}{$\begin{array}{l}\text { HES }(n=40) \\
\text { Mean (SD) }\end{array}$} & \multicolumn{4}{|c|}{ Independent Sample t-Test } \\
\hline & & & $\mathbf{t}$ & $\mathbf{p}$ & Mean diff. & (95\% C.I.) \\
\hline \multicolumn{7}{|l|}{ Hematocrit (\%) } \\
\hline Pre-operative & $38.5(3.23)$ & $39.28(1.8)$ & -1.327 & 0.188 & -0.77 & $(-1.94-0.39)$ \\
\hline Postoperative & $31.63(3.45)$ & $31.18(2.49)$ & 0.668 & 0.506 & 0.45 & $(-0.89-1.79)$ \\
\hline Change & $-6.88(3.78)$ & $-8.1(2.84)$ & 1.638 & 0.105 & 1.23 & $(-0.26-2.71)$ \\
\hline \multicolumn{7}{|c|}{ Platelets (X0.1 million cell $/ \mathrm{cmm}$ ) } \\
\hline Pre-operative & $2.50(0.64)$ & $2.36(0.6)$ & 0.981 & 0.329 & 0.14 & $(-0.14-0.41)$ \\
\hline Postoperative & $2.19(0.53)$ & $2.00(0.62)$ & 1.503 & 0.137 & 0.19 & $(-0.06-0.45)$ \\
\hline Change & $-0.31(0.41)$ & $-0.37(0.5)$ & 0.587 & 0.559 & 0.06 & $(-0.14-0.26)$ \\
\hline \multicolumn{7}{|c|}{ Serum creatinine (mg/dl) } \\
\hline Pre-operative & $0.94(0.15)$ & $0.97(0.17)$ & -1.054 & 0.295 & -0.04 & $(-0.11-0.03)$ \\
\hline Postoperative & $0.89(0.16)$ & $0.99(0.21)$ & -2.358 & 0.021 & -0.10 & $(-0.18--0.02)$ \\
\hline Change & $-0.05(0.14)$ & $0.01(0.2)$ & -1.663 & 0.100 & -0.06 & $(-0.14-0.01)$ \\
\hline \multicolumn{7}{|c|}{ Reaction time R (mm) } \\
\hline Pre-operative & $6.34(2.3)$ & $7.20(2.53)$ & -1.580 & 0.118 & -0.86 & $(-1.93-0.22)$ \\
\hline Postoperative & $4.96(1.69)$ & $5.66(1.77)$ & -1.816 & 0.073 & -0.70 & $(-1.47-0.07)$ \\
\hline Change & $-1.39(2.98)$ & $-1.54(2.92)$ & 0.231 & 0.818 & 0.15 & $(-1.16-1.47)$ \\
\hline \multicolumn{7}{|c|}{ Clot formation time $\mathrm{K}(\mathrm{mm})$} \\
\hline Pre-operative & $1.78(0.61)$ & $1.92(0.51)$ & -1.135 & 0.260 & -0.14 & $(-0.39-0.11)$ \\
\hline Postoperative & $1.47(0.45)$ & $1.72(0.66)$ & -1.960 & 0.054 & -0.25 & $(-0.50-0.00)$ \\
\hline Change & $-0.31(0.8)$ & $-0.20(0.8)$ & -0.588 & 0.558 & -0.11 & $(-0.46-0.25)$ \\
\hline \multicolumn{7}{|l|}{ Alpha angle } \\
\hline Pre-operative & $64.60(7.35)$ & 61.47 (8.35) & 1.780 & 0.079 & 3.13 & $(-0.37-6.63)$ \\
\hline Postoperative & $68.18(6.64)$ & $65.65(8.31)$ & 1.501 & 0.137 & 2.53 & $(-0.82-5.87)$ \\
\hline Change & $3.58(9.48)$ & $4.19(10.07)$ & -0.277 & 0.783 & -0.61 & $(-4.96-3.75)$ \\
\hline \multicolumn{7}{|c|}{ Maximum amplitude } \\
\hline Pre-operative & $69.81(5.61)$ & $67.95(5.41)$ & 1.505 & 0.136 & 1.86 & $(-0.60-4.31)$ \\
\hline Postoperative & $72.35(4.65)$ & $70.56(5.22)$ & 1.619 & 0.109 & 1.79 & $(-0.41-3.99)$ \\
\hline Change & 2.54 (5.77) & $2.61(6.82)$ & -0.046 & 0.963 & -0.07 & $(-2.88-2.75)$ \\
\hline
\end{tabular}

Figure 2 presents the intraoperative blood loss with HES and RL. 


\section{Cureus}

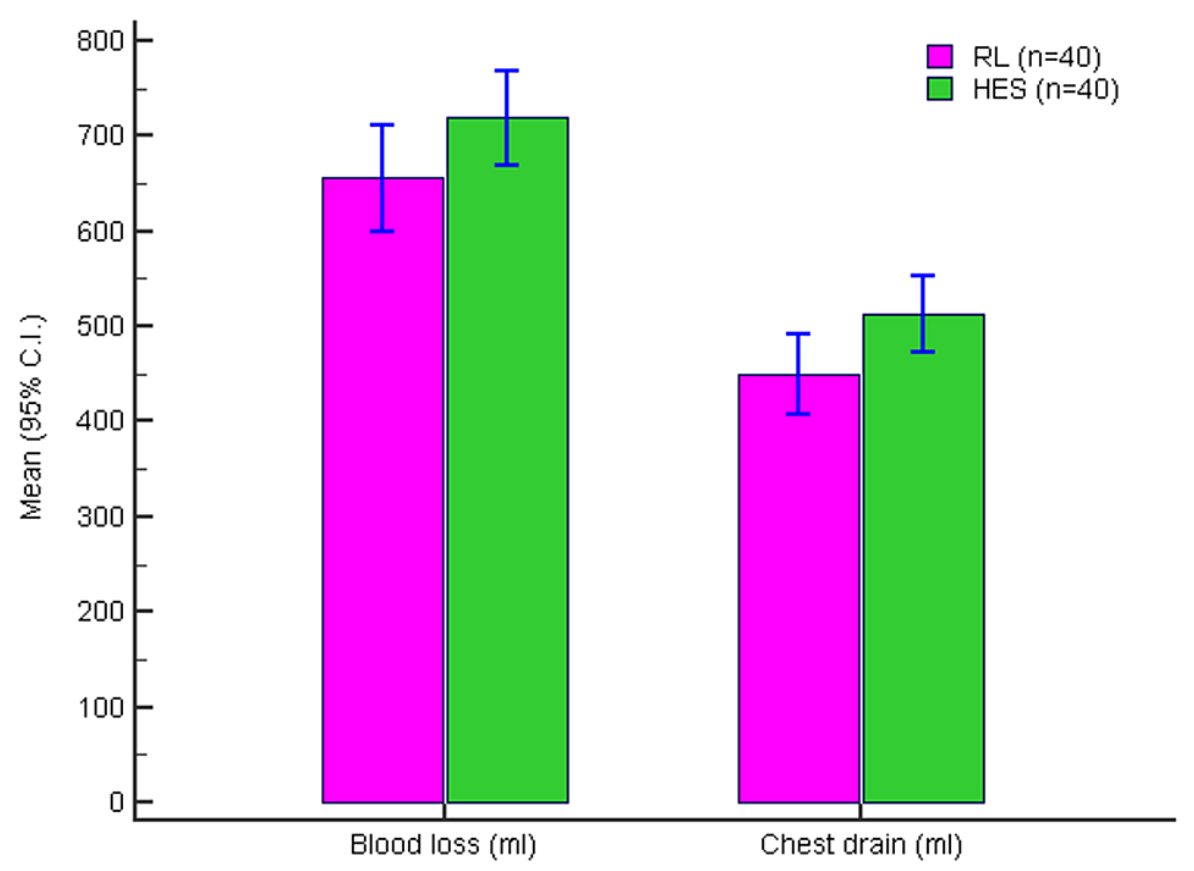

FIGURE 2: Intraoperative blood loss ( $\mathrm{ml}$ ) and chest drain volume $(\mathrm{ml})$ in two groups

RL: Ringer lactate; HES: hexaethyl starch.

Figure 3 presents the duration of ventilator use (hours) and the ICU stay (hours).

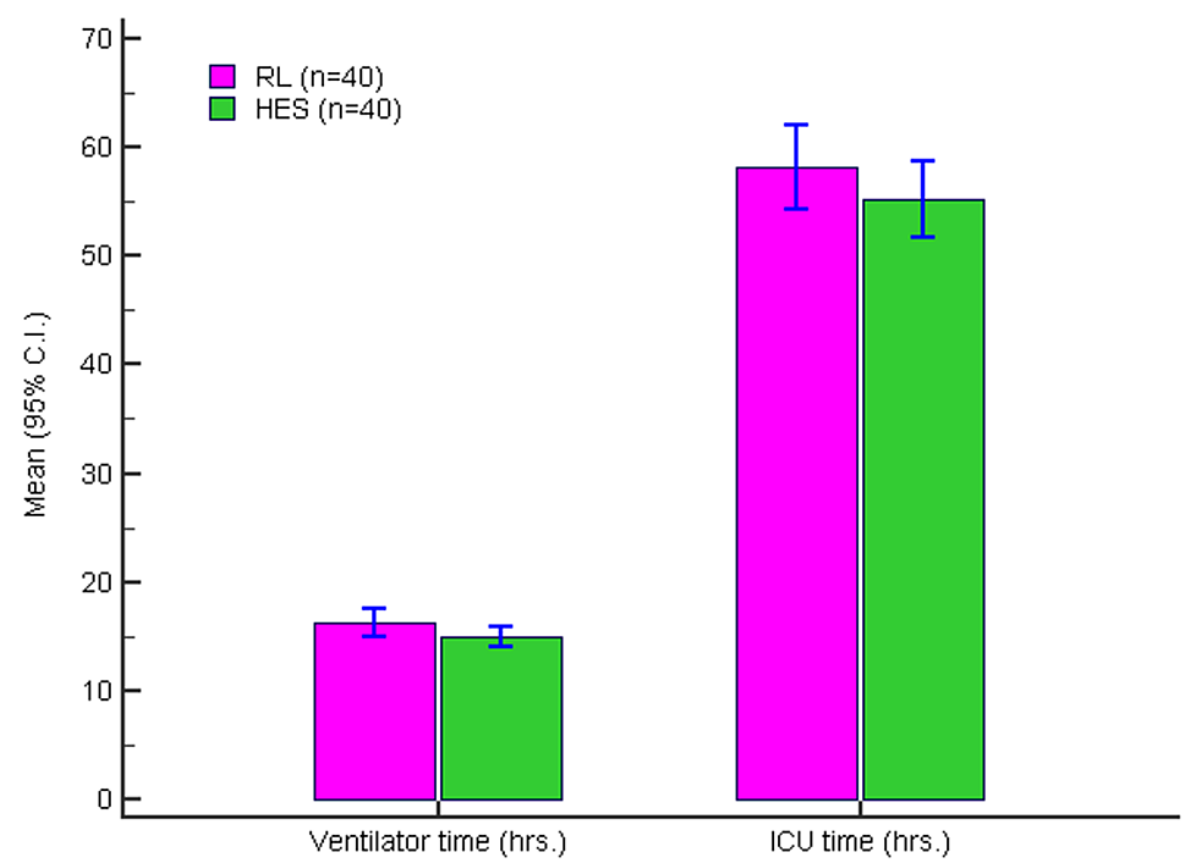

FIGURE 3: Duration of ventilator use (hrs) and ICU stay (hrs) in two groups

RL: Ringer lactate; HES: hexaethyl starch; ICU: intensive care unit. 
There were no differences between the HES and RL groups (adjusted for covariates) for change in laboratory parameters (Table 3). This signifies a similar safety profile of HES and RL.

\begin{tabular}{|c|c|c|c|c|}
\hline & $\begin{array}{l}\text { Unadjusted Mean } \\
\text { Difference }\end{array}$ & $\begin{array}{l}\text { Adjusted Mean } \\
\text { Difference* }\end{array}$ & P & $\begin{array}{l}\text { 95\% C.I. for the Adjusted Mean } \\
\text { Difference }\end{array}$ \\
\hline Hematocrit (\%) & 1.225 & 1.292 & 0.089 & $(-0.20-2.78)$ \\
\hline Platelets (lakh/cmm) & 0.060 & 0.044 & 0.663 & $(-0.16-0.24)$ \\
\hline Serum creatinine (mg/dl) & -0.063 & -0.072 & 0.064 & $(-0.15-0.00)$ \\
\hline Reaction tıme $\mathrm{R}(\mathrm{mm})$ & 0.153 & 0.059 & 0.932 & $(-1.31-1.42)$ \\
\hline $\begin{array}{l}\text { Clot formation time } \mathrm{K} \\
(\mathrm{mm})\end{array}$ & -0.105 & -0.062 & 0.737 & $(-0.43-0.31)$ \\
\hline Alpha angle & -0.605 & -0.746 & 0.741 & $(-5.23-3.73)$ \\
\hline Maximum amplitude & -0.065 & 0.031 & 0.983 & $(-2.85-2.91)$ \\
\hline \multicolumn{5}{|c|}{$\begin{array}{l}\text { TABLE 3: Unadjusted and adjusted means (ANCOVA) for change in laboratory parameters in two } \\
\text { groups }\end{array}$} \\
\hline \multicolumn{5}{|c|}{ * Adjusted for multiple comparisons with age, gender, BMI, and need for PRBC as covariates using ANCOVA. } \\
\hline \multicolumn{5}{|c|}{ PRBS: Packed red blood cells; BMI: body mass index; ANCOVA: multiple analysis of covariance. } \\
\hline
\end{tabular}

\section{Discussion}

Optimization of perioperative fluid therapy helps in reducing the morbidity and mortality associated with CABG. The type of fluid to be used is still controversial. Colloids have the theoretical advantage of greater retention in the intravascular compartment, thereby reducing the fluid requirement. However, a high cost and higher chances of coagulopathy and renal injury limit its use. The various side effects associated with first and second degree HES such as coagulopathy, anaphylactoid reactions, renal impairment, and increase in serum amylase levels led to development of newer starch-based volume expanders like $6 \%$ hydroxyethyl starch 130/0.4 [11]. The molecular weight and degree of substitution may be mainly responsible for varying effects of different HES solutions on hemostasis [4]. However, there are very few studies that directly compare the effect on coagulation between 6\% hydroxyethyl starch 130/0.4 and crystalloids. An in-vitro study by Casutt et al. (2010) found fewer effects on blood coagulation using crystalloids than colloids [12]. Skhirtladze et al. (2014) found greater hemodilution and interference with coagulation with colloids when compared with crystalloids leading to greater need for blood transfusion [10]. In another prospective casecontrol study involving $50 \mathrm{CABG}$ patients receiving acute normovolemic hemodilution (ANH), there were no significant changes in coagulation state with saline solution (SS) [13]. However, Ruttmann et al. (2002) reported rapid pre-operative hemodilution with crystalloids leading to enhanced coagulation as against no enhancement of coagulation with colloids [14]. Low molecular weight-hydroxyethyl starch (LMW-HES) 130/0.4 was better than medium molecular weight-hydroxyethyl starch (MMW-HES) 200/0.5 and gelatin in patients undergoing off-pump (OP)-CABG, in terms of better preservation of coagulation associated with enhanced volume effect [15]. In a randomized, double-blind clinical trial, HES (6\%) had a better volumeexpanding effect than gelatin (4\%) and Ringer's solutions, and its short-term effects on renal function were also better than gelatin and Ringer's solutions [16]. In a prospective, randomized clinical trial, 132 patients undergoing CABG, administration of tranexamic acid in HES 130/0.4 prime solution study group decreased the estimated blood loss and chest tube drainage in comparison to patients receiving Ringer prime solution with or without tranexamic acid postoperatively [17]. In a randomized, controlled study similar to ours involving adults after on-pump CABG procedures, there was no significant difference in blood loss or blood coagulation between the 130/0.4 (HES 6\%) group and the gelatin group [18].

We compared the effect of RL solution versus HES (130/0.4) 6\% solution on intraoperative and postoperative blood loss when used as the main infusion during cardiac surgery in patients after CABG surgery. In our study, there was no significant difference in the extent of hemodilution seen in the two groups. The postoperative chest tube drainage was higher in the HES group, but that did not lead to any significant increase in the need for blood transfusion. This can be explained by the lower cut-off hemoglobin of $7 \%$ for transfusing blood, which we followed in the study. The reduction in total fluid requirement in the HES group did not translate into any reduction in the ICU and overall hospital length of stay. Alteration of coagulation and renal function assessed by thromboelastography (TEG), serum creatinine, and urine output was also 
The concentration of intravenous (IV) solution influences the initial volume effect, i.e., $6 \%$ HES solutions is iso-oncotic in vivo, with $1 \mathrm{~L}$ replacing about $1 \mathrm{~L}$ of blood loss, whereas $10 \%$ solutions are hyperoncotic, with a volume effect considerably exceeding the infused volume (about $145 \%$ ). The HES (130/0.4) $6 \%$ is a low molecular weight third-generation starch prepared to have minimal effects on the coagulation, kidney, and serum amylase levels apart from being less immunogenic [11]. Also, in a meta-analysis including 73 randomized trials comparing clinical outcomes in adult patients receiving colloids in the perioperative period, HES preparations were associated with a $15 \%$ reduction in blood loss compared to gelatin and pentastarches [11]. Crystalloids, on the other hand, are aqueous solutions of mineral salts or other watersoluble molecules. Although crystalloids come in a variety of formulations, a preparation like RL with an ionic composition close to that of plasma may be referred to as "balanced" or "physiological" [19]. The primary recognized difference between crystalloid and colloid solutions is the ability of colloid solutions to maintain or improve colloid osmotic pressure for longer periods in comparison with crystalloid solutions in which colloid osmotic pressure may be reliably reduced through hemodilution [20,21]. This is especially important in patients that have significant blood loss. Our study probably involved a very experienced surgical team that has caused minimal blood loss, and this could be the reason we did not found any differences in the two groups with respect to blood loss and the hemodynamic effects. However, as the amount of surgical blood loss increases, the maintenance of a normal colloid oncotic pressure may not be possible without the administration of a colloid solution. Even though crystalloids are theoretically associated with higher blood loss as compared to colloids, we observed that the blood loss was similar to RL and HES in our study.

The study had few limitations in terms of a small sample size and a study restricted to one indication and a single tertiary care center. Our study involved less intraoperative blood loss, but the hemodynamic parameters may be altered during moderate to severe blood loss, and the patients may require colloid or vasodilators. Hence, the observations could not be generalized to other surgical conditions and the entire population.

\section{Conclusions}

Crystalloids may be a safe and cost-effective fluid replacement option during perioperative period in patients undergoing OP-CABG cardiac surgery in economically challenged countries. However, further large-scale multicenter studies with varied indications are recommended to substantiate the equivalence of crystalloids to colloids in perioperative management.

\section{Additional Information}

\section{Disclosures}

Human subjects: Consent was obtained or waived by all participants in this study. Institutional Ethics Committee, Apollo Hospital, Chennai issued approval IEC/AH-Anes/2013/007. The study documents were reviewed and approved by the IEC, and the study was conducted in accordance with the principles of good clinical practice (GCP). Informed written consent was obtained from all subjects before their participation. Animal subjects: All authors have confirmed that this study did not involve animal subjects or tissue. Conflicts of interest: In compliance with the ICMJE uniform disclosure form, all authors declare the following: Payment/services info: All authors have declared that no financial support was received from any organization for the submitted work. Financial relationships: All authors have declared that they have no financial relationships at present or within the previous three years with any organizations that might have an interest in the submitted work. Other relationships: All authors have declared that there are no other relationships or activities that could appear to have influenced the submitted work.

\section{Acknowledgements}

The authors thank Dr. Nityanand, Dr. Shubha, and Dr. Supraja for their sincere and active participation in the study. The authors also thank Dr. MR Girinath and Dr. Deepak Langade for their contributions.

\section{References}

1. Yatin M, Ajay D, Sujatha Z, Meharwal, Naresh T: Comparison of new HES (130.0.4) and HES (200.0.5) in OPCAB surgery. J Anesth Clin Pharmacol. 2007, 23:273-278. 10.5830/CVJA-2012-026

2. Russell JA, Navickis RJ, Wilkes MM: Albumin versus crystalloid for pump priming in cardiac surgery: metaanalysis of controlled trials. J Cardiothorac Vasc Anesth. 2004, 18:429-37. 10.1053/j.jvca.2004.05.019

3. Boldt J, Brosch Ch, Röhm K, Papsdorf M, Mengistu A: Comparison of the effects of gelatin and a modern hydroxyethyl starch solution on renal function and inflammatory response in elderly cardiac surgery patients. Br J Anaesth. 2008, 100:457-64. 10.1093/bja/aen016

4. Treib J, Haass A, Pindur G: Coagulation disorders caused by hydroxyethyl starch . Thromb Haemost. 1997, 78:974-83.

5. Dart AB, Mutter TC, Ruth CA, Taback SP: Hydroxyethyl starch (HES) versus other fluid therapies: effects on kidney function. Cochrane Database Syst Rev. 2010, 1:CD007594. 10.1002/14651858.CD007594.pub2

6. Rehm M, Orth V, Scheingraber S, Kreimeier U, Brechtelsbauer H, Finsterer U: Acid-base changes caused by 
$5 \%$ albumin versus $6 \%$ hydroxyethyl starch solution in patients undergoing acute normovolemic hemodilution: a randomized prospective study. Anesthesiology. 2000, 93:1174-83. 10.1097/00000542200011000-00007

7. Brunkhorst FM, Engel C, Bloos F, et al.: Intensive insulin therapy and pentastarch resuscitation in severe sepsis. N Engl J Med. 2008, 358:125-39. 10.1056/NEJMoa070716

8. Kozek-Langenecker SA: Effects of hydroxyethyl starch solutions on hemostasis . Anesthesiology. 2005, 103:654-60. 10.1097/00000542-200509000-00031

9. Surgenor SD, Kramer RS, Olmstead EM, et al.: The association of perioperative red blood cell transfusions and decreased long-term survival after cardiac surgery. Anesth Analg. 2009, 108:1741-6. 10.1213/ane.0b013e3181a2a696

10. Skhirtladze K, Base EM, Lassnigg A, Kaider A, Linke S, Dworschak M, Hiesmayr MJ: Comparison of the effects of albumin $5 \%$, hydroxyethyl starch $130 / 0.46 \%$, and Ringer's lactate on blood loss and coagulation after cardiac surgery. Br J Anaesth. 2014, 112:255-64. 10.1093/bja/aet348

11. Westphal M, James MF, Kozek-Langenecker S, Stocker R, Guidet B, Aken HV: Hydroxyethyl starches: different products--different effects. Anesthesiology. 2009, 111:187-202. 10.1097/ALN.0b013e3181a7ec82

12. Casutt M, Kristoffy A, Schuepfer G, Spahn DR, Konrad C: Effects on coagulation of balanced (130/0.42) and non-balanced (130/0.4) hydroxyethyl starch or gelatin compared with balanced Ringer's solution: an in vitro study using two different viscoelastic coagulation tests ROTEMTM and SONOCLOTTM. Br J Anaesth. 2010, 105:273-81. 10.1093/bja/aeq173

13. Jalali A, Naseri MH, Chalian M, Dolatabadi HL: Acute normovolaemic haemodilution with crystalloids in coronary artery bypass graft surgery: a preliminary survey of haemostatic markers. Acta Cardiol. 2008, 63:335-9. 10.2143/AC.63.3.1020310

14. Ruttmann TG, James MF, Finlayson J: Effects on coagulation of intravenous crystalloid or colloid in patients undergoing peripheral vascular surgery. Br J Anaesth. 2002, 89:226-30. 10.1093/bja/aef179

15. Muralidhar K, Garg R, Mohanty S, Banakal S: Influence of colloid infusion on coagulation during off-pump coronary artery bypass grafting. Indian J Anaesth. 2010, 54:147-53. 10.4103/0019-5049.63653

16. Alavi SM, Ahmadi BB, Baharestani B, Babaei T: Comparison of the effects of gelatin, Ringer's solution and a modern hydroxyl ethyl starch solution after coronary artery bypass graft surgery. Cardiovasc J Afr. 2012, 23:428-31. 10.5830/CVJA-2012-026

17. Yanartas M, Baysal A, Aydın C, et al.: The effects of tranexamic acid and 6\% hydroxyethyl starch (HES) solution (130/0.4) on postoperative bleeding in coronary artery bypass graft (CABG) surgery. Int J Clin Exp Med. 2015, 15:5959-71.

18. Kimenai DM, Bastianen GW, Daane CR, Megens-Bastiaanse CM, van der Meer NJ, Scohy TV, Gerritse BM: Effect of the colloids gelatin and HES 130/0.4 on blood coagulation in cardiac surgery patients: a randomized controlled trial. Perfusion. 2013, 28:512-9. 10.1177/0267659113491446

19. American Thoracic Society: Evidence-based colloid use in the critically ill: American thoracic society consensus statement. Am J Respir Crit Care Med. 2004, 170:1247-59. 10.1164/rccm.200208-909ST

20. Martin GS, Lewis CA: Fluid management in shock. Semin Respir Crit Care Med. 2004, 25:683-93. 10.1055/s2004-860982

21. Stephens RC, Mythen MG: Saline-based fluids can cause a significant acidosis that may be clinically relevant. Crit Care Med. 2000, 28:3375-7. 10.1097/00003246-200009000-00064 